\title{
Pulmonary oedema at necropsy: a combined pathological and radiological method of study
}

\author{
GERARD SLAVIN, LOUIS KREEL, AMANDA HERBERT, AND BRENDA SANDIN \\ From the Departments of Histopathology and Radiology, Northwick Park Hospital and Clinical Research \\ Centre, Harrow, Middlesex
}

SYNOPSIS Fixation of lungs at necropsy by inflation with formaldehyde vapour was used in a combined radiological and pathological study of pulmonary oedema. Pulmonary oedema was found in $79 \%$ of lungs examined. The earliest phases affect the interstitial tissue with oedematous connective tissue planes and distension of pulmonary lymphatics. These changes may be associated with reduction in the compliance of the lung. Alveolar filling is a late stage in the accumulation of oedema fluid in the lungs.

Pulmonary oedema is one of the commonest lesions seen at necropsy. It occurs in association with a diversity of pathological conditions and often as a terminal event. Cameron (1948) showed that the frequency of severe pulmonary oedema was marked in association with cardiovascular disease, cerebral lesions, and trauma such as multiple fractures, but that it was common also in the terminal phase of many illnesses. However, its frequency and its apparently unexciting histological features have diverted the interest of morbid anatomists from pulmonary oedema. It is a secondary phenomenon but it is not of secondary importance for it gives rise to gross disturbances in pulmonary function and may be the immediate cause of death.

Pulmonary oedema at necropsy may be estimated inexactly by gross weighing of the excised lungs and by the demonstration of free fluid exuding from the cut surfaces of the lungs. Histological examination confirms the presence of pulmonary oedema but unless multiple sections are taken in a systematic fashion the sum of these methods may offer little or no information concerning the amount or distribution of oedema in the lung. Moreover, with the development of intensive care units, pathologists are required to provide services on patients whose pulmonary function has been monitored in detail up to the time of death. In these patients standard necropsy procedures are particularly inadequate in the assessment of interstitial pulmonary oedema with a minor or no alveolar component.

Lungs fixed by a formaldehyde vapour inflation technique (Wright, Slavin, Kreel, Callan, and Sandin, 1974) without any fluid condensation or instillation Received for publication 13 January 1975. into the lungs have been studied. The lungs are fixed in a position of inflation; radiolucency of the lungs is maintained, and combined radiological and pathological studies of the excised lungs are possible. This paper records experience of this technique in the demonstration of pulmonary oedema.

\section{Material and Methods}

Lungs from 150 unselected clinical necropsies were examined after formaldehyde vapour fixation. Most necropsies were performed more than 24 hours after death. Coroner's necropsies were not included in the study. The period of fixation was usually overnight. The fixed lungs were $x$-rayed in anteroposterior and lateral views. The lungs were then sliced with a ham knife at $1.0 \mathrm{~cm}$ and the slices were radiographed again. Tissue blocks for histological examination were selected from the nakedeye lesions in the lung slices, from radiologically observed lesions, and from multiple random sites. Correlations were made between radiological appearances and the subsequent histological demonstration of pulmonary oedema so that with experience the radiological features were recognized and used to map the anatomical locations of pulmonary oedema. In addition, vapour fixation allowed morphological studies of pulmonary oedema in inflated lungs undistorted by the addition of large quantities of liquid fixative.

\section{Results}

Pulmonary oedema was seen radiologically and confirmed by microscopy in 106 of the 150 lungs 
Total lungs examined

Oedema not identified

Oedema detected by radiology, confirmed by histology .

Interstitial oedema only

Interstitial and alveolar oedema

Oedema identified by histology alone
150

$3121 \%$

106

$53 \%$

$10167 \%$

$139 \%$
Table I Frequency of pulmonary oedema

examined. In 13 lungs oedema was demonstrated histologically which had not been seen on the radiographs (table I). These figures represent the presence or absence of oedema, and no attempt to grade the severity of the process was made. In particular, the interstitial component was frequently well marked but in association with only a minor degree of alveolar filling. A quantitative study of the distribution of pulmonary oedema and its relative amounts in the various compartments of the lungs is in progress (Slavin, Herbert, and Krzel, 1975).

\section{MACROSCOPIC APPEARANCES}

On slicing the lung prepared by this technique fluid does not run from the cut surface as in the markedly oedematous fresh lung. The surfaces are moist, but in areas which subsequently prove to have marked haemodynamic pulmonary oedema a brown discolouration of the surface may be seen. Interstitial on and septal oedema may be recognized by undue 0 prominence of rather gelatinous bands or septa. Oedema may also be recognized by a change in the texture of the lungs which feel stiff and firmer than usual.

\section{RADIOLOG Y}

Radiological examination of the lungs whole and sliced shows two basic morphological patterns:

(a) There may be undue prominence of septal lines and interstitial fascial sheaths or paravascular $\underset{\infty}{\sim}$ connective tissue planes, which correspond to $G$ interstitial oedema and are seen as various types of $\dot{w}$ linear opacities (fig 1).

(b) Small punctate opacities may produce a 을 white 'ground glass' appearance which corresponds $\rightarrow$ to the presence of intra-alveolar oedema. This appearance typically spares the peripheral cortex, and such sparing may help radiographic distinction $\vec{\varphi}$ between pneumonic consolidation and confluent or oedema (fig 2).

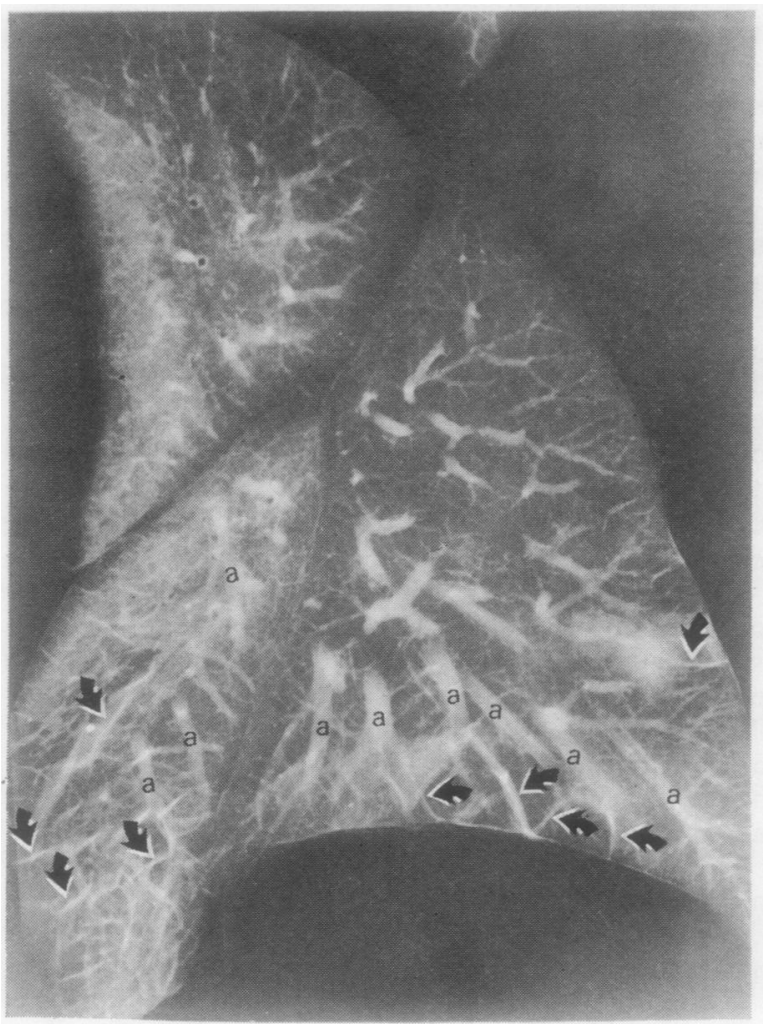

Fig 1 Radiograph of a $1 \mathrm{~cm}$ slice of lung showing marked interstitial pulmonary oedema. The oedema lines (arrows) are of variable calibre and extend between pleura, bronchovascular bundles, and veins. They are distinguished from arteries (a) which are regularly distributed and taper and branch without reaching the pleural surface. 


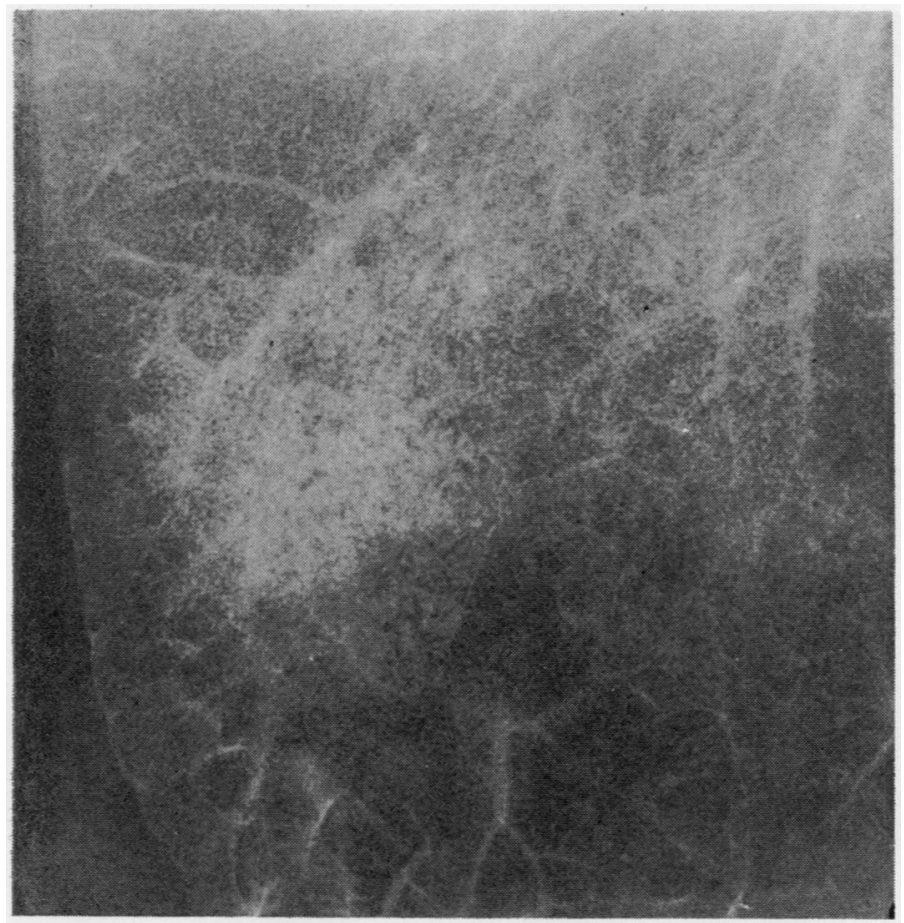

Fig 2 There is intra-alveolar oedema showing multiple tiny pinpont opacities and producing a ground glass appearance obscuring the vascular pattern when it becomes confluent. Note how the peripheral part of the lung is relatively spared by alveolar oedema.

The radiological lines are an early manifestation of pulmonary oedema and are equivalent to A, B, and D lines recognized in life (Kerley, 1962; Kreel, Slavin, Herbert, and Sandin, 1975). They may be seen as the sole manifestation of pulmonary oedema or in association with the ground glass appearance in more severe cases. The localization of such radiological lines is partly determined by preformed septa and partly by fascial planes within the interstitium of the lung. Thus they are frequently seen at the angles of the lungs where fascial septa are common (Reid, 1959). Oedematous paravascular tissues may also give rise to linear shadows, and frequently thick band-like oedematous lines appear to originate from paravascular regions. The punctate ground glass appearance may be seen as a generalized or regional phenomenon corresponding to alveolar oedema in large areas of the lungs. It is consistently more marked at the bases of the lungs and increases in the posterior and upper zones when the oedema becomes more generalized. Except in very gross pulmonary oedema, punctate shadowing tends to be much less in the anterior parts of the lung and in the middle lobe. By contrast, thick band shadows of interstitial pulmonary oedema (D lines) are more marked anteriorly although only minimal or no alveolar oedema is recognized in the adjacent lung on the radiographs (Kreel et al, 1975). Intra-alveolar oedema may also be recognized as a component of a local lesion in association with a pulmonary infarct or inflammatory disease.

\section{HISTOLOGICAL APPEARANCES}

This method of preparation and block selection draws attention to early interstitial forms of pulmonary oedema as well as the later forms where alveolar flooding is easily recognizable. In static morphological studies of necropsy material it is not possible to ascertain the exact sequence of fluid accumulation but it is possible to recognize characteristic morphological changes due to excess fluid in the various tissues of the lung and to correlate these with the clinical and radiological features.

(1) There is an expansion of the perivascular, peribronchiolar, and interstitial connective tissue space by oedema fluid. Such fluid may be largely confined to the periarterial sheath (fig 3). Fascial planes and septa may be seen swollen with eosinophilic oedema fluid (fig 4). Lymphatics in these connective tissue planes may be dilated, and similar subpleural lymphatics are frequently prominent beneath oedematous pleura (fig 5). These changes 


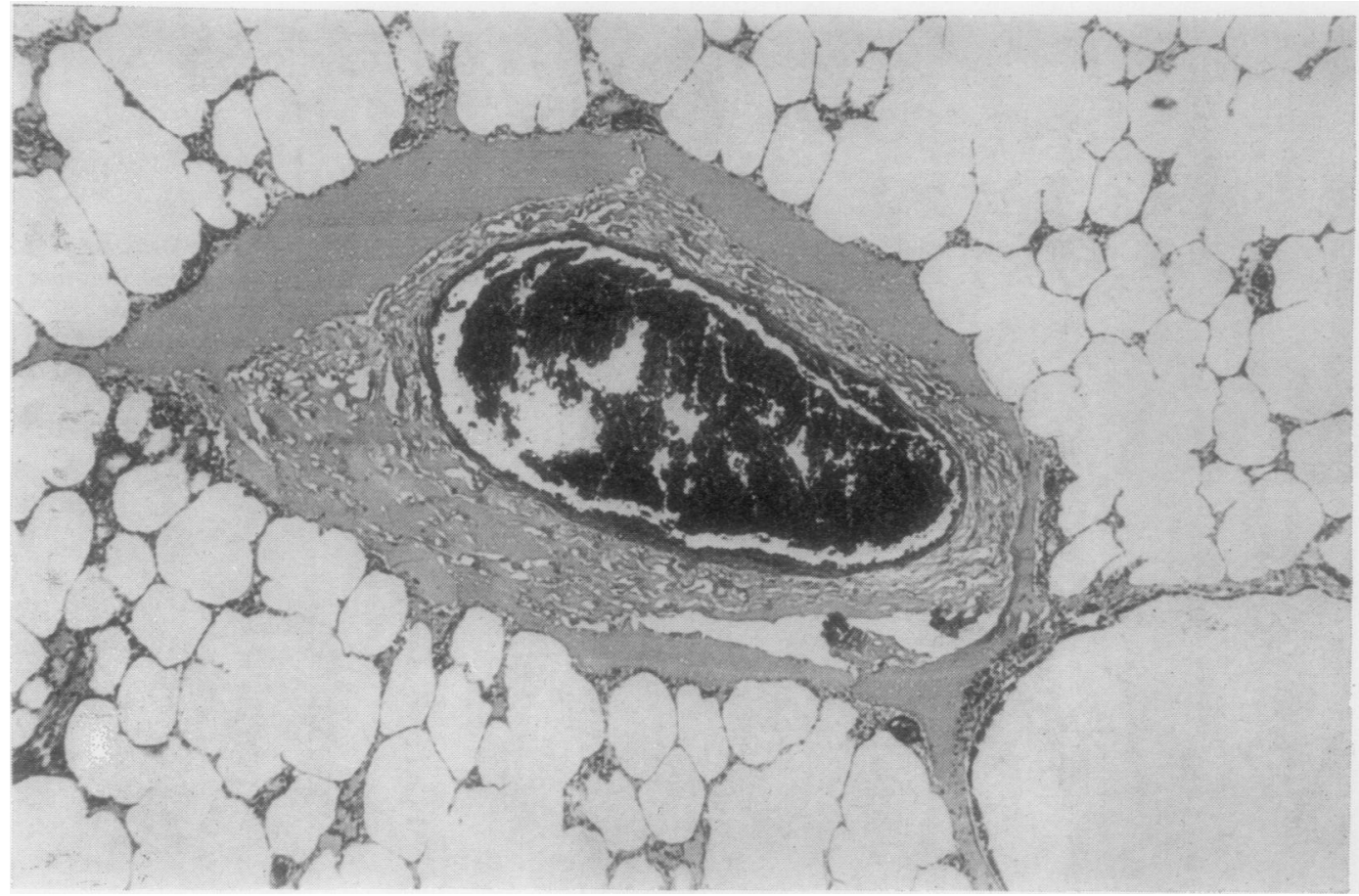

Fig 3 Interstitial oedema in paravascular connective tissue. Note the small amount of alveolar oedema predominantly seen in the angles of alveolar sacs. (Haematoxylin and eosin $\times 55$ ).

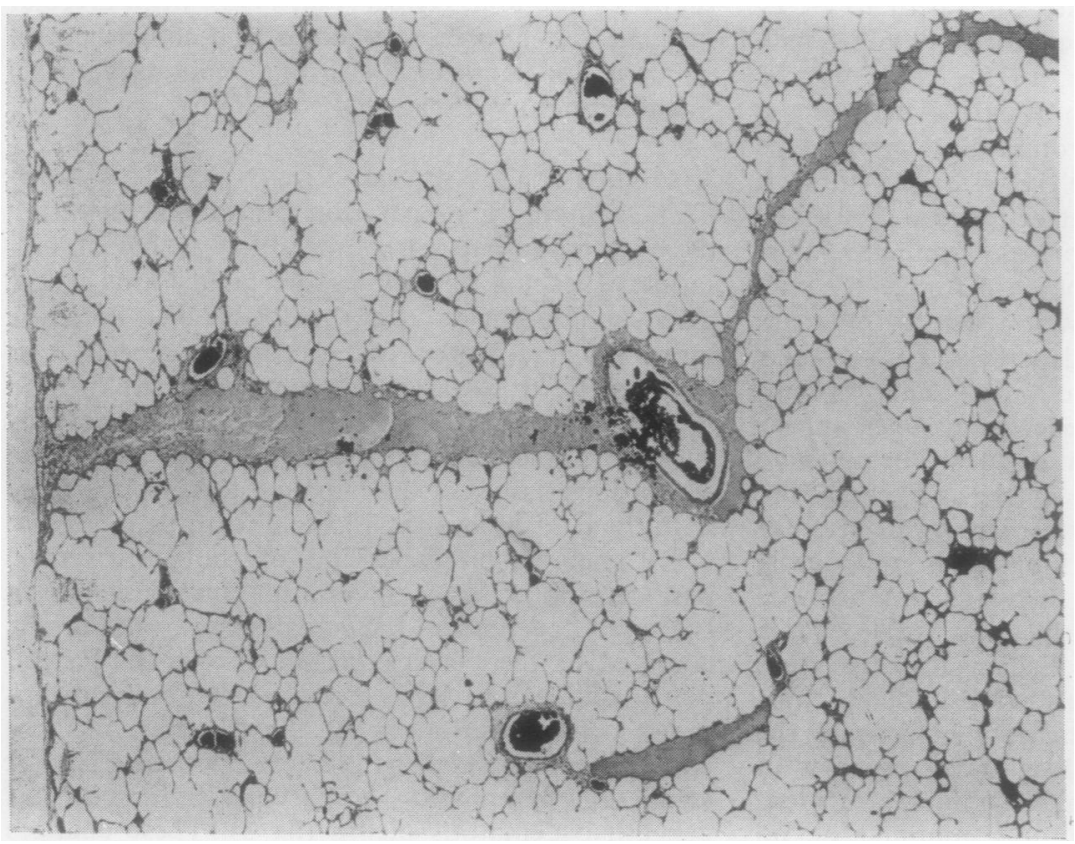

Fig 4 A short oedematous $\frac{3}{3}$ fascial plate runs from the pleural surface and contains a distended lymphatic. This lesion was recognized on the. radiograph as a Kerley ' $B$-lin $(H$ and $E \times 16)$

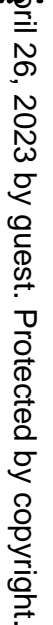




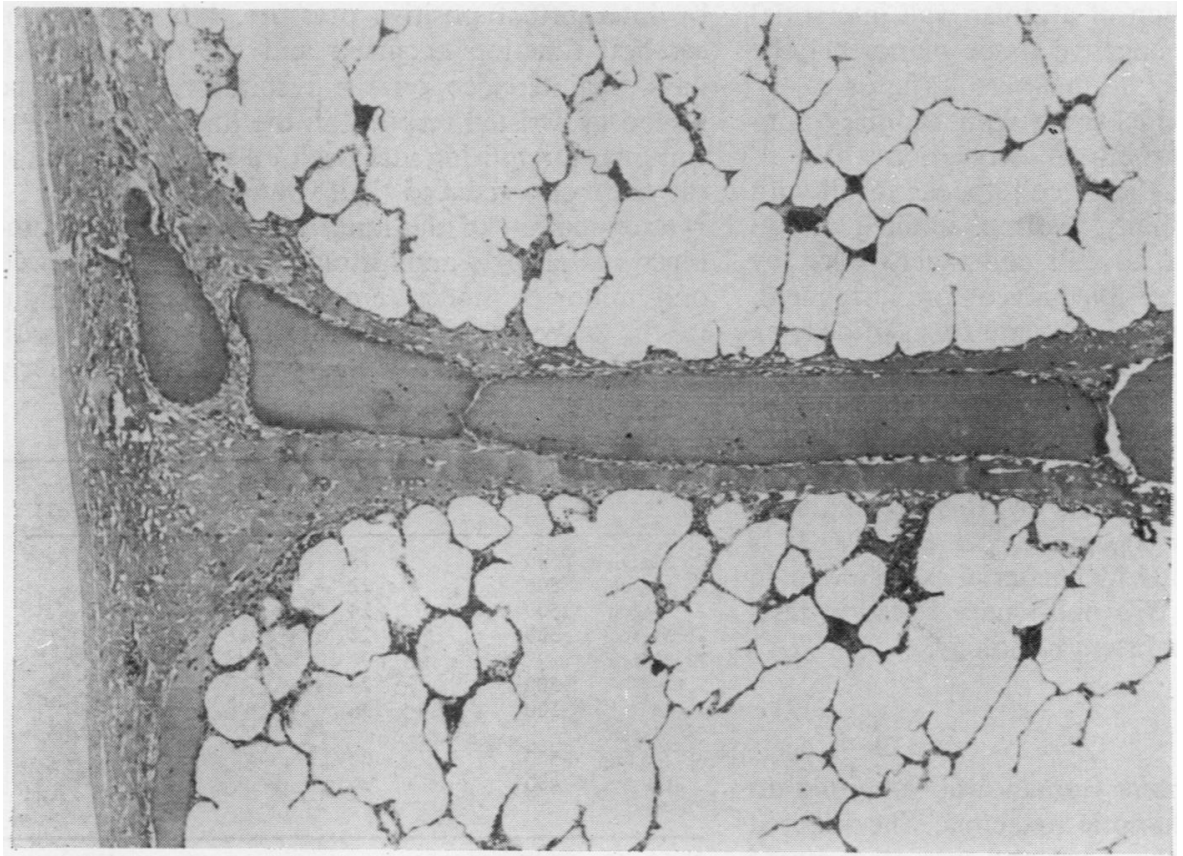

Fig 5 Distended

lymphatics are seen subpleurally and extend along an oedematous connective tissue septum. ( $H$ and $E$ $\times 55)$

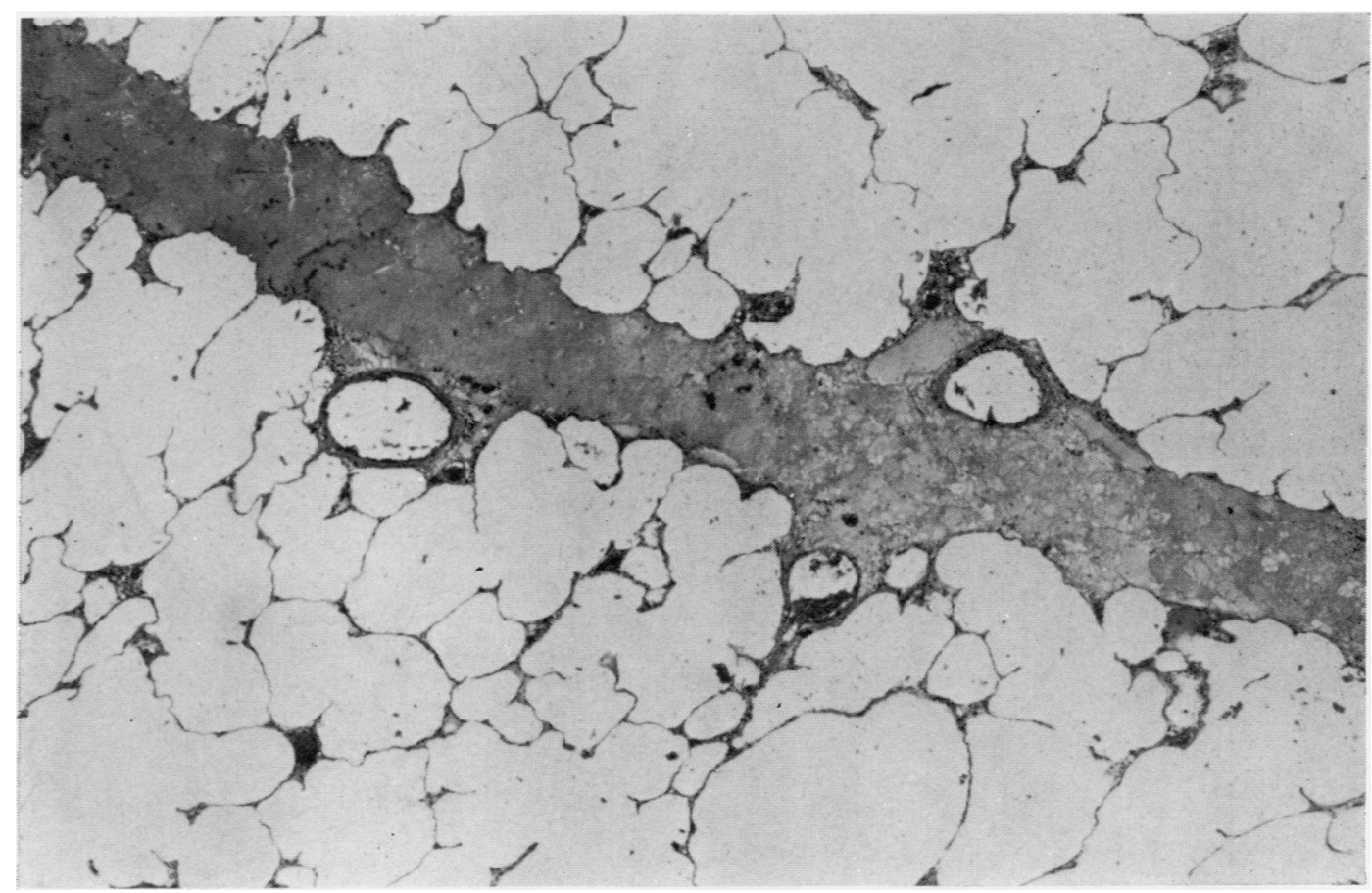

Fig 6 Oedematous intralobular connective tissue plane containing blood vessels and lymphatics. Note the lack of oedema in adjacent alveoli. ( $H$ and $E \times 55$ ) 
anticipate the expansion of alveolar wall interstitial space, and swollen connective tissue planes may be seen next to essentially normal alveoli (fig 6).

(2) Alveolar wall thickening with capillary congestion is noted but usually in association with

(3) alveolar filling: the alveoli appear to fill with oedema fluid individually. Normal unfilled alveoli may be seen next to alveoli completely filled by fluid. Intermediate, half-filled alveoli are infrequent, but some alveoli may show arcuate zones of oedema at the corners of the alveolus while the remainder contains air (fig 7). The extent of alveolar filling is variable, but ultimately confluent pulmonary oedema occurs (fig 8).

Examination of the lungs by this technique is valuable as a purely morphological exercise. It is particularly valuable if the material is reviewed in conjunction with in vivo pulmonary function tests and in vivo and postmortem radiology.

\section{Case Report}

A 22-year-old pregnant woman was admitted to hospital with pre-eclamptic toxaemia. She suffered a cardiac arrest on the ward and was resuscitated but remained comatose. Respiration was maintained by intermittent positive pressure. No recovery of cerebral function occurred and she died after 10 days' maintenance on the respirator. During thes period of assisted respiration the lungs became less? compliant, requiring increased inflation pressure foㅡㅡㅁ the same or a reduced tidal volume (table II).

Examination of the lungs after death by a com $\approx$ bined radiological and histological technique showects only minor or moderate quantities of oedema fluidin the alveoli but gross interstitial oedema with distended interstitial septa, particularly anteriorly $\vec{\omega}$

\begin{tabular}{|c|c|c|c|}
\hline Date & Tidal Vol $(\mathrm{ml})$ & $\begin{array}{l}\text { Inflation Pressure } \\
\left(\mathrm{CmH}_{2} \mathrm{O}\right)\end{array}$ & $\begin{array}{l}\text { Compliance } \\
\left(\mathrm{ml} / \mathrm{cmH} \mathrm{H}_{2} \mathrm{O}\right)\end{array}$ \\
\hline $\begin{array}{l}25 \text { March } \\
26 \text { March } \\
27 \text { March } \\
28 \text { March } \\
29 \text { March }\end{array}$ & $\begin{array}{l}500 \\
500 \\
500 \\
500\end{array}$ & $\begin{array}{l}18 \\
22 \\
24 \\
24\end{array}$ & $\begin{array}{l}25 \\
22 \\
21 \\
21\end{array}$ \\
\hline am & $\begin{array}{l}500 \\
500\end{array}$ & $\begin{array}{l}24 \\
26\end{array}$ & $\begin{array}{l}21 \\
19\end{array}$ \\
\hline $\begin{array}{r}5.0 \mathrm{am} \\
10.0 \mathrm{am}\end{array}$ & $\begin{array}{l}500 \\
400\end{array}$ & $\begin{array}{l}30 \\
30\end{array}$ & $\begin{array}{l}17 \\
13\end{array}$ \\
\hline
\end{tabular}

Table II Evidence of increasing lung stiffness during intermittent positive pressure respiration

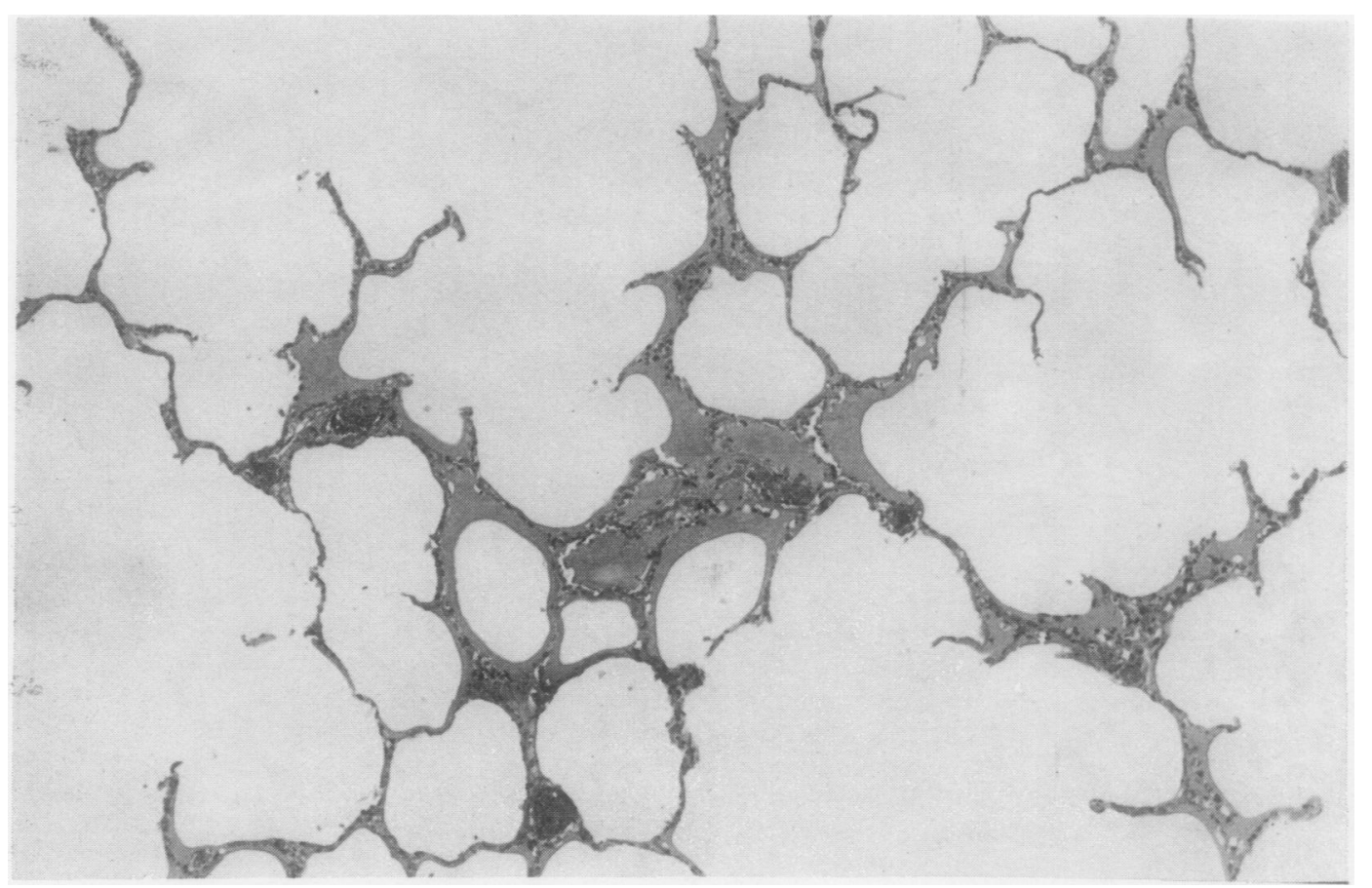

Fig 7 Intra-alveolar oedema. Fluid-filled alveoli are seen adjacent to normal air-filled sacs. Partially filled sacs are scanty but note presence of small fluid arcs at angles of alveoli. $(H$ and $E \times 80)$ 


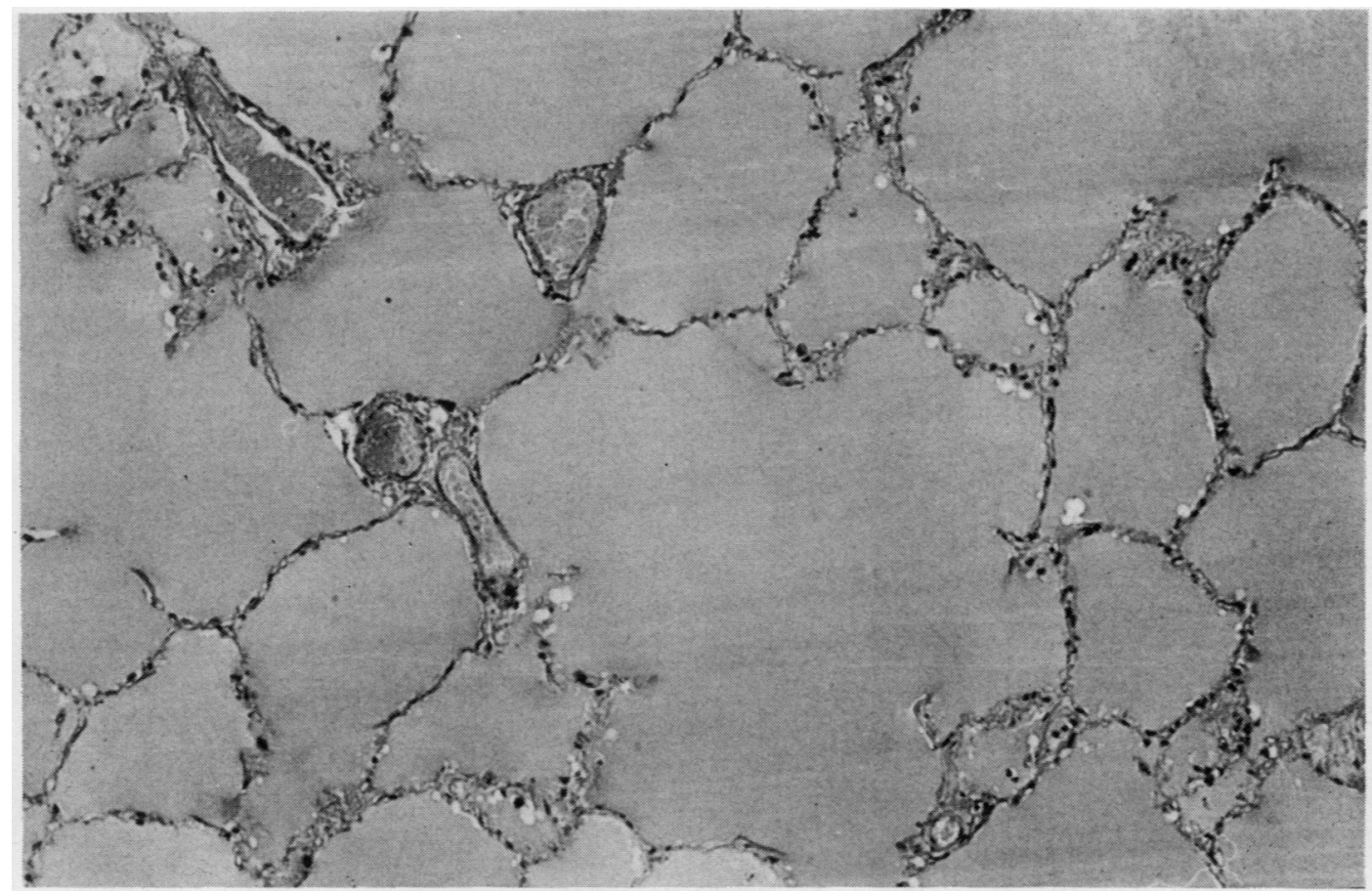

Fig 8 Confluent oedema with intra-alveolar flooding. ( $H$ and $E \times 80)$

and at the angles of the lungs (fig 9 a-d). It was concluded that the decreased compliance was accounted for at least in part by the marked oedema in the interstitial component.

\section{Discussion}

The frequency of pulmonary oedema in these necropsies $(79 \%)$ is greater than that in the series reported by Cameron $(1948 ; 65 \%$ ) using conventional techniques though there is some selection in our material in the exclusion of coroner's cases. This increase may reflect the help given by radiographs of lung slices in selecting blocks for histological examination and particularly in the recognition of distended and oedematous connective tissue planes before the phase of alveolar flooding.

The lung is not a dry organ but the pathways of normal fluid movements are not clear. Fluid leaving normal alveolar vessels, either capillaries or venules, passes into the interstices of the alveolar wall to lymphatics in interstitial tissue. This fluid does not normally enter the alveolar spaces but may move under the direction of a subatmospheric pressure in the interstitial tissue (Staub, 1970; Staub, 1974), reaching the systemic circulation via pulmonary lymphatics.
Pulmonary oedema occurs when there is an excess accumulation of fluid in the various pulmonary compartments. Haemodynamic oedema may arise in association with increased left atrial pressure as in congestive cardiac failure, while toxins such as alloxan (Cottrell, Levine, Senior, Wiener, Spiro, and Fishman, 1967), alpha-naphthyl thiourea, high concentrations of oxygen (Meyrick, Miller, and Reid, 1972), and bacterial toxins (Finegold, 1967) may induce pulmonary oedema following direct damage to endothelial cells.

In experimental animals haemodynamic pulmonary oedema appears to result from an accentuation of the normal process of fluid exchanges within the lung (Cottrell et al, 1967; Szidon, Pietra, and Fishman, 1972). There is an increase in the rate of fluid and protein flow before any recognizable increase in extravascular fluid content. The earliest changes seen on electron microscopy show that excess water accumulates in those portions of alveolar septa rich in connective tissue fibres. Such early changes are not visible by light microscopy but in dogs light microscopy shows that pulmonary oedema develops in a constant morphological sequence (Staub, Nagano, and Pearce, 1967). There is expansion of the perivenous and peribronchiolar sheaths by oedema fluid and distension of septal lymphatics. Only at a late 


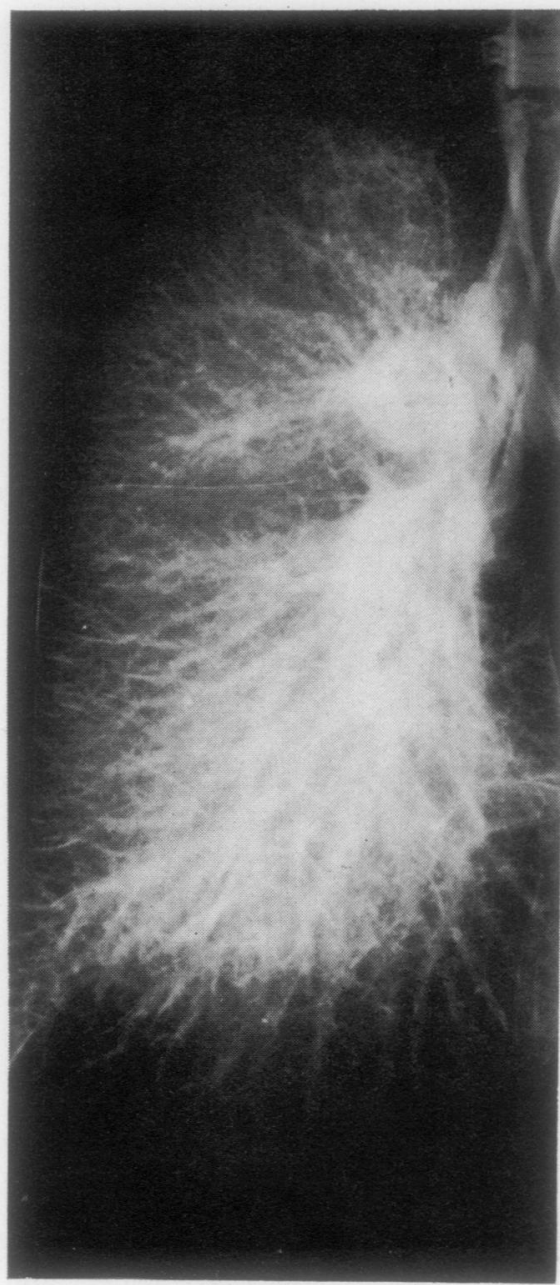

Fig 9a

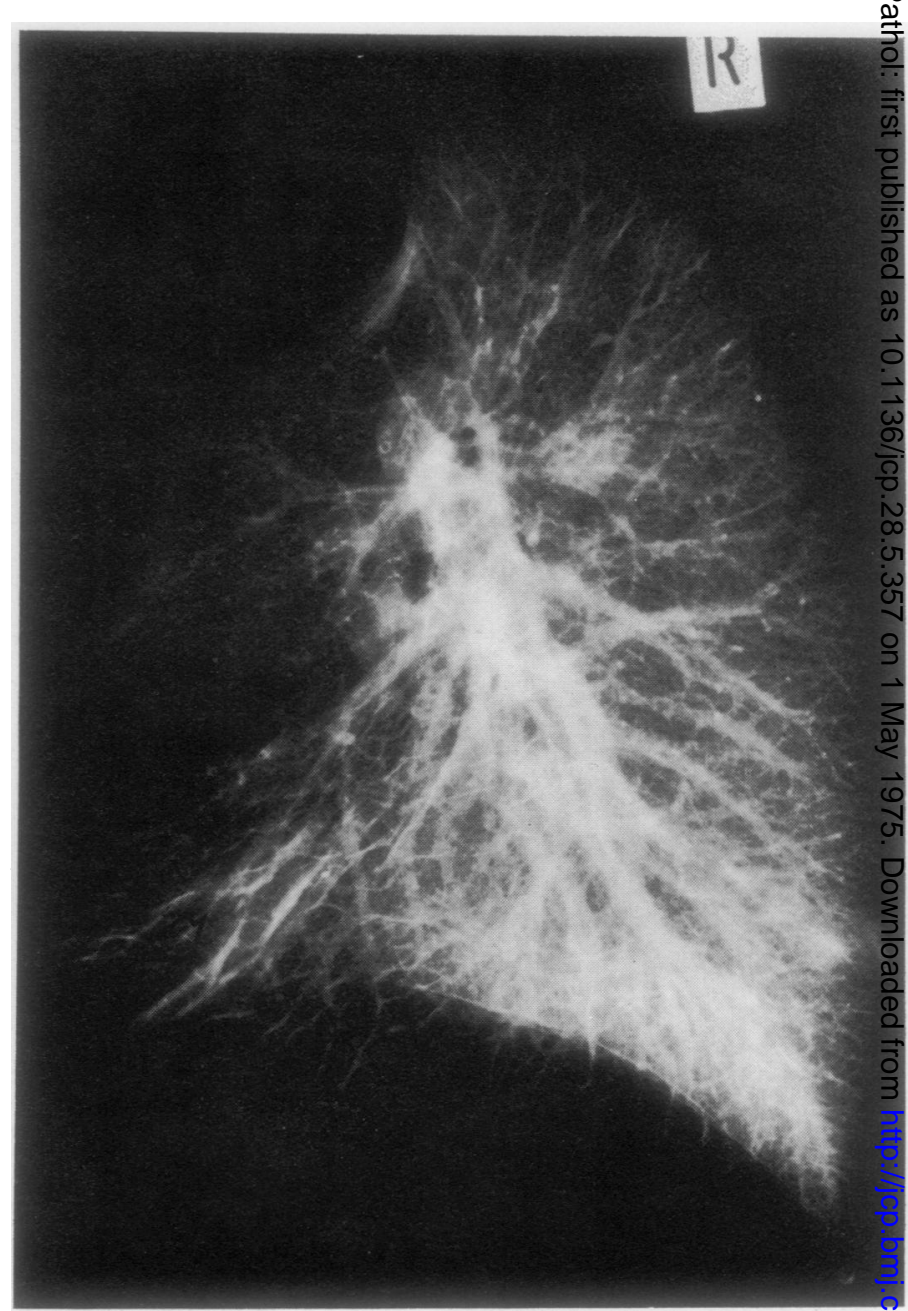

Fig 9b

Fig 9a Frontal view of a formaldehyde vapour inflated right lung showing moderate basal oedema seen as a ground glass whiteness. Multiple oedema line shadows are also present.

Fig $9 \mathrm{~b}$ Lateral view showing moderate posterior basal intra-alveolar oedema which decreases from the base towards the upper lobe. Note the thick bands of interstitial oedema shown anteriorly (black arrow head) but without intraalveolar component.

stage does fluid fill the alveolar spaces. In pulmonary oedema due to toxic endothelial damage marked interstitial oedema is present and precedes the formation of alveolar fluid (Finegold, 1967; Meyrick et al, 1972). These experimental studies have provided strong evidence that the loose interstitial connective tissue space is a preferential site of initial fluid accumulation in pulmonary oedema, both haemodynamic and toxic in origin.

By contrast, morphological descriptions of pulmonary oedema in man lay relatively minor stress on the interstitial component and place much more emphasis on late stage flooded, fluid-filledo alveoli (Spencer, 1968; Roberts, 1970; Millard, 1971). $₫$ The same emphasis is reflected in standard clinical ? texts (Braunwald, 1974) in which signs and symptoms $\frac{T}{-}$ of established pulmonary oedema are stressed at the $\frac{\vec{\Phi}}{\mathbb{D}}$ expense of the signs of early pulmonary oedema. $\stackrel{\mathbb{D}}{\mathbb{P}}$ Some change in attitude has developed with the $\stackrel{\mathbb{Q}}{\stackrel{1}{ }}$ growth of intensive care units. Pulmonary inter- $\bar{O}$ stitial oedema is marked in burned and shocked 0 patients (Nash, Foley, and Langlinais, 1974), and응 


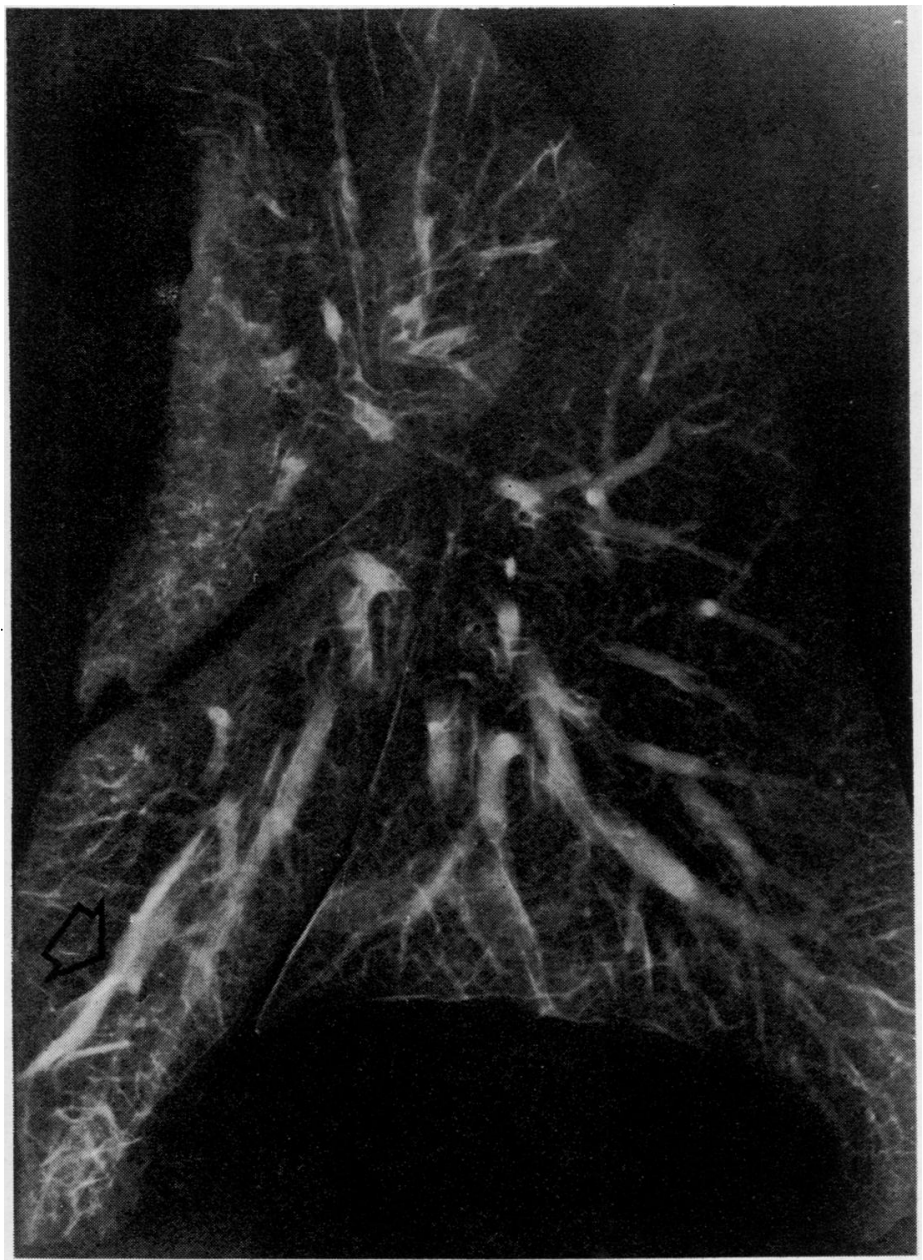

Fig 9c $1 \mathrm{~cm}$ slice of right lung in lateral view showing very thick bands of interstitial oedema. There are also many thin interstitial lines but note the relative lack of shadowing due to intra-alveolar pulmonary oedema.

Fig 9d There is gross interstitial oedema with thickened septa connecting pleura, bronchovascular bundles, and veins. ( $H$ and $E \times 4)$

Fig. 9c

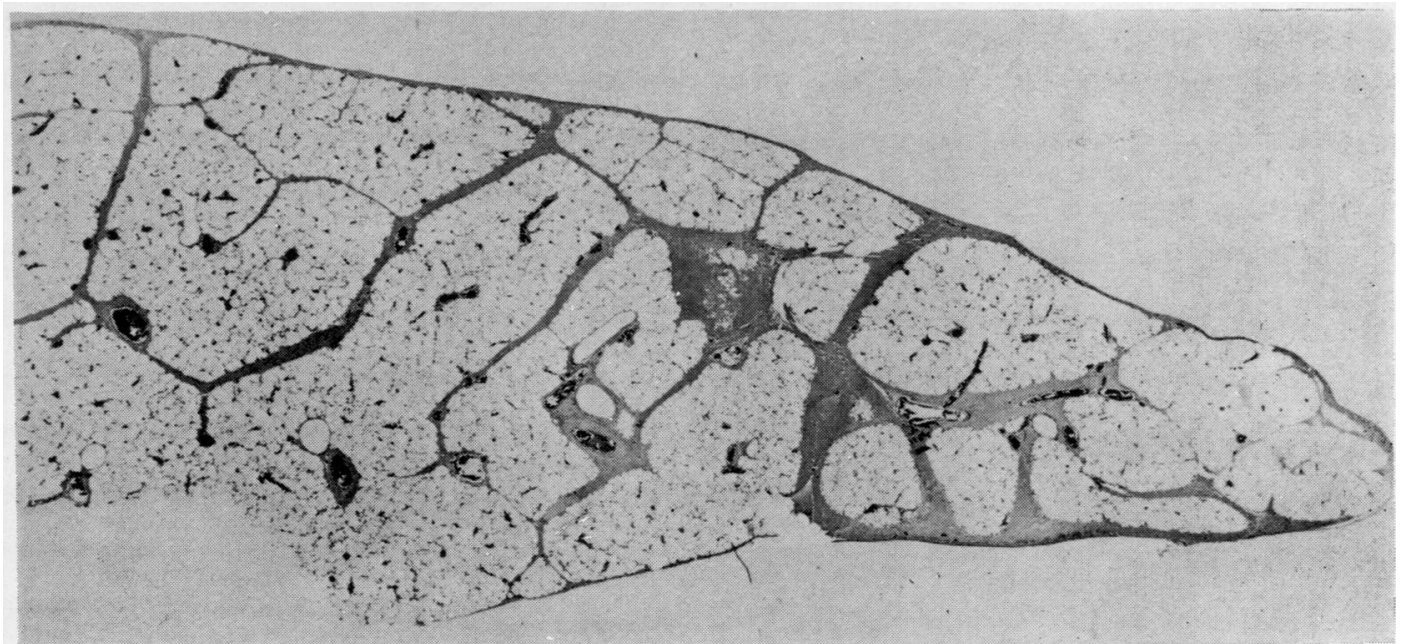

Fig. 9d 
it may be that the alterations of compliance as well as alterations in gas exchange are due to the accumulation of fluid about small airways (Pietra, 1974).

Satisfactory morphological examination of the lungs for oedema must direct attention to changes in the interstitial tissues as well as to those occurring in the alveoli. Such examination needs to be at macroscopic level to establish the anatomical distribution of oedema supplemented by histological examination to ascertain the exact microscopical location of the excess fluid. Fixation with formaldehyde vapour leaves the lungs in a position of inflation and with maintenance of in vivo radiolucency. In lungs with pulmonary oedema postmortem radiology clearly demonstrates interstitial oedema in the form of Kerley's A and B lines, by D lines, and by widening of bronchovascular bundles. Alveolar oedema is manifested by a punctate ground glass opacity. A series of films of $1 \mathrm{~cm}$ slices form a permanent record mapping the distribution of the oedema in 'anatomical tomograms'. Moreover blocks for histological examination may be taken in conjunction with and as a control of the radiological appearances.

The development of pulmonary oedema in a single patient cannot be studied but some dynamic aspects may be inferred by consideration of the static patterns recognized in films from many patients with various degrees of oedema. There is an initial prominence of interstitial lines followed by intra-alveolar oedema. These changes are most marked at the bases and posterior parts of the lung, extending in more severe cases to the upper anterior parts of the lung in a regular sequence. Too few cases have as yet been studied to identify a different morphological pattern of development between the haemodynamic pulmonary oedema associated with congestive cardiac failure and those cases associated with endothelial damage due to toxins as in Gramnegative septicaemia.

The combined radiological and histological features seen in these lungs emphasize that in man as in experimental animals the earlier phases of pulmonary oedema seen by light microscopy affect the interstitial tissue, and that alveolar filling is a late stage in the accumulation of excess water in the lungs. Clinical recognition of this interstitial phase is difficult and imprecise. Changes in mechanical properties of the lungs such as decreased compliance may be a pointer, especially if changes are measured serially in an individual patient. Improved in vivo radiological techniques have been stimulated by these combined studies (Kreel et al, 1975) and are helpful in the early recognition of interstitial oedema, but all such methods need clinicopathological correlations in cases followed to

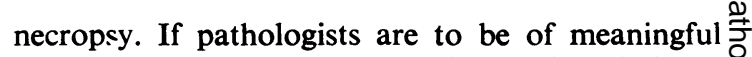
help in such studies they must adapt their techniques to demonstrate the earlier stages of interstitial $\overrightarrow{\vec{F}}$ oedema as well as the more easily discerned alveolar flooding and to delineate accurately the anatomical distribution of such oedema in the pulmonary tissues.

We wish to thank Miss Christine Bateman for the preparation of the histological sections.

\section{References}

Braunwald, E. (1974). Heart failure. In Harrison's Principles of Internal Medicine, edited by W. M. Wintrobe, G. W. Thorner, R. D.:Adams, E. Braunwald, K. J. Isselbacher, and R. G. Petersdorf, 4th ed., pp. 1117-1127. McGraw-Hill, New York.

Cameron, G. R. (1948). Pulmonary oedema. Brit. med. J., $\rightarrow$ 1, 965-972.

Cottrell, T. S., Levine, O. R., Senior, R. M., Wiener, J. Spiro, D., and Fishman, A. P. (1967). Electron microscopic alterations at the alveolar level in pulmonary edema. $\overrightarrow{0}$ Circulat. Res., 21, 783-797.

Finegold, M. J. (1967). Interstitial pulmonary edema. Lab Invest., 16, 912-924.

Kerley, P. (1962). Occupational diseases of lungs. In Text Book of $X$-ray Diagnosis, edited by S. C. Shanks and P. Kerley, 3rd ed., vol. 2. Lewis, London.

Kreel, L., Slavin, G., Herbert, A., and Sandin, B. (1975). ํํㅇ Intralobar septal oedema: D Lines. Clin. Radiol. (In@ press).

Meyrick, B., Miller, J., and Reid, L. (1972). Pulmonary을 oedema induced by ANTU, or by high or low oxygen concentrations in rat. Brit. J. exp. Path., 53, 347-358.

Millard, M. (1971). Lung, pleura and mediastinum. I Pathology, edited by W. A. D. Anderson, 6th ed. vol. 2, pp. 875-997. Mosby, St. Louis.

Nash, G., Foley, F. D., and Langlinais, P. C. (1974). Pulmonary interstitial edema and hyaline membranes in adul $\underline{B}$. burn patients. Hum. Path., 5, 149-160. Pietra, G. G. (1974). The lung in shock. Hum. Path., 5 ,
121-122.

Reid, L. (1959). The connective tissue septa in the adull human lung. Thorax, 14, 138-145.

Roberts, K. B. (1970). Oedema. In General Pathology edited by Lord Florey, 4th ed., pp. 370-393. Lloyd-Luke London.

Slavin, G., Herbert, A., and Kreel, L. (1975). Unpublished

Spencer, H. (1968). Pathology of the Lung, 2nd ed. Per gammon Press, Oxford.

Staub, N. C. (1970). The pathophysiology of pulmonary edema. Hum. Path., 1, 419-432.

Staub, N. C. (1974). Pulmonary edema. Physiol. Rev., 54 है

Staub, N. C., Nagano, H., and Pearce, M. L. (1967) Pulmonary edema in dogs, especially the sequence of fluid accumulation in lungs. $J$. appl. Physiol., 22, 227-240울

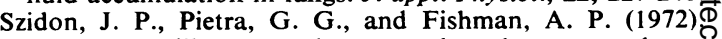
Alveolar-capillary membrane and pulmonary edema $\frac{\mathscr{D}}{\mathbb{D}}$ New Engl. J. Med., 286, 1200-1204.

Wright, B. M., Slavin, G., Kreel, L., Callan, K., and Sandinס B. (1974). Postmortem inflation and fixation of human lungs. Thorax., 29, 189-194. 